\section{High Temperature Micromechanical Behavior of a Pt-Modified Nickel Aluminide Bond-Coating and of Its Interdiffusion Zone with the Superalloy Substrate}

\author{
DAMIEN TEXIER, DANIEL MONCEAU, \\ SERGE SELEZNEFF, ARNAUD LONGUET, \\ and ERIC ANDRIEU
}

The micromechanical properties of a $\beta-(\mathrm{Ni}, \mathrm{Pt}) \mathrm{Al}$ bondcoating was investigated between $700^{\circ} \mathrm{C}$ and $1000^{\circ} \mathrm{C}$ using ultrathin freestanding bond-coating specimens. Its brittle-to-ductile transition temperature was close to $750^{\circ} \mathrm{C}$, with a significant ductility above $800^{\circ} \mathrm{C}$ (up to 23 pct at $1000^{\circ} \mathrm{C}$ ). The tensile strength decreased from $450 \mathrm{MPa}$ at $750^{\circ} \mathrm{C}$ down to $50 \mathrm{MPa}$ at $1000^{\circ} \mathrm{C}$. Fractographic observations evidenced the material brittleness at intermediate temperature with large cleaved grains and its ductility above $750{ }^{\circ} \mathrm{C}$ with important necking of individual grains.

In service, turbine blades undergo thermomechanical stresses at elevated temperatures in harsh operating conditions (high temperature oxidation and corrosion). Nickel-based single-crystal superalloys overlaid with thermal barrier coating (TBC) has proven for decades to ensure a reliable design of such critical components for several thousands of hours of flights. ${ }^{[1]}$ TBC systems are constituted of a thermally insulated yttria partially stabilized zirconia (YSZ) top-coat deposited on top of a bond-coating, commonly made of $\beta$-(Ni,Pt)Al or

DAMIEN TEXIER is with the Institut Clement Ader (ICA) UMR CNRS 5312, Université de Toulouse, CNRS, INSA, UPS, Mines Albi, ISAE-SUPAERO, Campus Jarlard, 81013 Albi Cedex 09, France. Contact e-mail: damien.texier@mines-albi.fr DANIEL MONCEAU and ERIC ANDRIEU are with the CIRIMAT-UMR CNRS 5085, Université de Toulouse, ENSIACET, 4 Allée Emile Monso, BP 44362, 31030, Toulouse Cedex 4, France. SERGE SELEZNEFF and ARNAUD LONGUET are with SAFRAN Aircraft Engines, Rond-Point René Ravaud, 77550 MoissyCramayel, France.
MCrAlY alloys. The zirconia top-coat aims to significantly lower the temperature seen by the bond-coating $\left(\Delta T \approx 100-150^{\circ} \mathrm{C}\right)$, and thus using blade superalloys at gas environment temperatures higher than their melting temperature. Therefore, the thermomechanical integrity of $\mathrm{TBC}$ systems, its damage and lifetime prediction in service conditions are of major concern for land-based gas turbines and aero-engines. ${ }^{[2-5]} \beta$ $(\mathrm{Ni}, \mathrm{Pt}) \mathrm{Al}$ or MCrAlY bond-coatings are functionally selected to protect the superalloy against high temperature oxidation/corrosion but also to provide cohesive properties between the zirconia top-coat and the superalloy. However, $\beta$-(Ni,Pt)Al bond-coatings exhibit a highly brittle behavior up to intermediate temperature $\left(T^{\circ} \mathrm{C}=700-800^{\circ} \mathrm{C}^{[6-8]}\right)$ This high brittle-to-ductile transition temperature (BDTT) makes it vulnerable to cracking during service, especially at low temperatures, and against foreign/domestic object impact. Such cracking in the coating can potentially lead to premature failure of the coated component, then rapidly propagating under cyclic thermomechanical loading. ${ }^{[9-13]}$ Crack propagation from initially cracked coatings are particularly deleterious for the integrity of the coated components. Property requirements are thus needed for the bond-coating to enhance $\mathrm{TBC}$ lifetime, i.e. (i) to provide bonding and strain accommodation properties between the zirconia top-coat and the superalloy, (ii) to avoid premature crack initiation due to a sufficiently low BDTT, (iii) to be creep-resistant at elevated temperature to limit rumpling during thermal cycling, and (iv) to limit interdiffusion within the superalloys not to undermine the original mechanical performance of the nickelbased superalloy. ${ }^{[6,9,14-16]}$ Therefore, assessing the local thermal and mechanical properties of the bond-coating and the gradient of these properties within this diffusion coating system is particularly important. Indeed, such a database is necessary for materials selection and for feeding numerical models predicting both the high temperature mechanical behavior and the service life of these layered structural components subjected to very complex thermal, mechanical, and thermomechanical stresses, especially in the thermal transient regime.

Thin-walled components such as turbine blade airfoil can be as thin as $500 \mu \mathrm{m}$ - and even thinner in a next future - of single-crystal nickel-based superalloy coated with a 30 to $50 \mu \mathrm{m}$ thick $\beta$-(Ni,Pt)Al bond-coating and an interdiffussion zone of 20 to $50 \mu \mathrm{m}$. Owing to the thicknesses of these different layers, the direct measurement of the thermal and mechanical properties of the bond-coating and the interdiffusion zone is not trivial. For decades, the validation of the mechanical performances of the coated components was performed on macrosize coated specimens or on bulky materials with a similar chemical composition of the bond-coating but with a different microstructure and potentially different extrinsic properties. The decay in mechanical properties between coated and uncoated components, the 
development of premature cracks within the brittle coating, and the temperature at which cracks develop were criteria driving the material selection for TBC systems, ${ }^{[9,10,14,17]}$ in addition to their high temperature oxidative and corrosive performance. Despite such characterization means aim to draw damage-tolerant maps of materials for given thermomechanical loadings, they are not capable to directly evaluate the local mechanical properties within the TBC system necessary for more accurate simulations for behavioral and lifetime predictions. Therefore, high temperature micromechanical approaches on freestanding coating specimens, ${ }^{[7,18-22]}$ microindentation approaches, ${ }^{[23,24]}$ and inverse identifications approaches on thin coated specimens with substrate ${ }^{[25,26]}$ were conjointly developed to ascertain the local mechanical properties of the different layers. While the direct measurement of the mechanical properties on freestanding coating specimens is particularly suited for materials identification, all these approaches are required to evaluate the local properties within the different layers but also the interactions between the different layers due to diffusion-process mechanisms at high temperature. Furthermore, ductility of bond-coating assessed with microtensile testing ${ }^{[7,19,20]}$ is not consistent with the one obtained with miniaturized disc bending testing ${ }^{[18]}$ or tensile testing on macroscopic coated specimens. ${ }^{[9,10,14,17]}$ Therefore, new micromechanical testing apparatus was recently developed to better assess both the tensile strength and the ductility of tensto-hundred micrometer-thick samples at elevated temperatures. ${ }^{[7,18-22]}$

In the present study, the tensile behavior of a freestanding $\beta$-(Ni,Pt)Al diffusion coating was investigated at high temperature and compared with the literature in a temperature window around the brittleto-ductile transition behavior of the platinum-modified aluminide bond-coating. In addition, the evolution of properties within the gradient of microstructure for this reference diffusion coating system was characterized for the first time layer by layer, i.e. the bond-coating (B.C.), the interdiffusion zone (ID.Z.), and the superalloy substrate (S.X.).

A Pt-modified nickel aluminide bond-coating was deposited on a flat single-crystal nickel-based superalloy (AM1) ingot with a nominal composition as follow (at. pct):Ni-8.6Cr-6.7Co-1.4Mo-1.8W-11.4Al-1.4Ti-2.6Ta.

The AM1 flat ingot was solidified along the [001] crystallographic direction with Bridgman-Stockbarger technique. Lateral faces of the AM1 flat ingot were parallel to [100] and [010] directions. The AM1 flat ingot was subjected to a solution heat treatment at $1300^{\circ} \mathrm{C}$ for 3 hours before coating. The deposition process of the Pt-modified nickel aluminide bond-coating on the superalloy substrate consisted of: (1) an electrodeposition of a platinum layer with a thickness of 6 to $8 \mu \mathrm{m}$, (2) a diffusion treatment at $1100{ }^{\circ} \mathrm{C}$ under high vacuum for 1 hour, and (3) an aluminization treatment using the APVS (Aluminization Phase Vapeur Snecma) process, as detailed in Reference 27. After the deposition process, the coated AM1 flat ingot was finally subjected to $870^{\circ} \mathrm{C}$ for 16 hours, followed by air quenching. The entire system heat treatment, allowing the homogenization of the superalloy and the substrate-coating interdiffusion, provides the so-called "as-received" microstructure, optimized in terms of mechanical properties for the AM1 substrate and surface reactivity. The microstructure of the coated system consisted in an external $\beta$-(Ni,Pt)Al layer thick of $30 \mu \mathrm{m}$ with coarse grains, a fine grain interdiffusion zone with a thickness of 20 to $25 \mu \mathrm{m}$ constituted of $\beta, \gamma^{\prime}$ and topologically close packed (TCP) phases rich in Mo, W, and Ta (see Figure 1). Alumina grit particles were observed at the original interface between $\mathrm{Pt}$ and the nickel-based

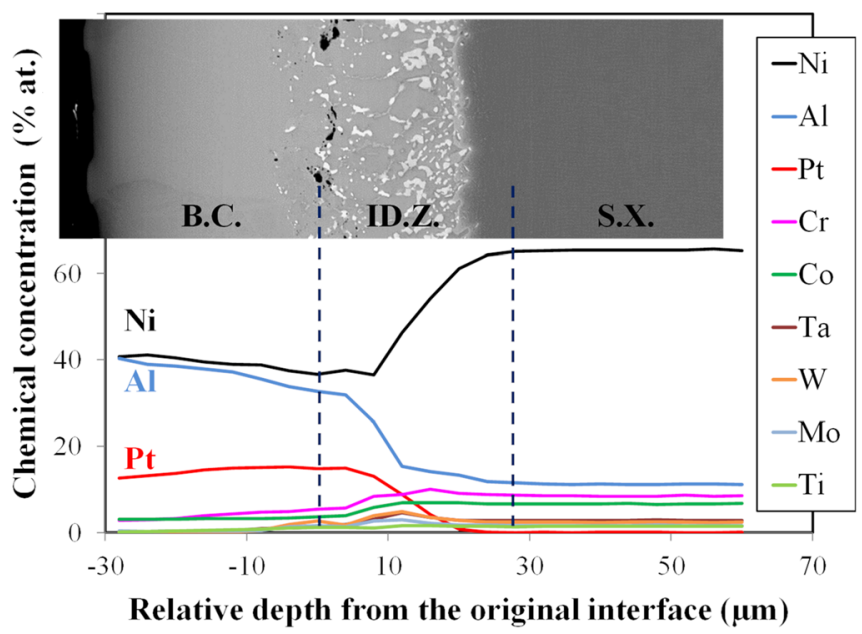

(a)

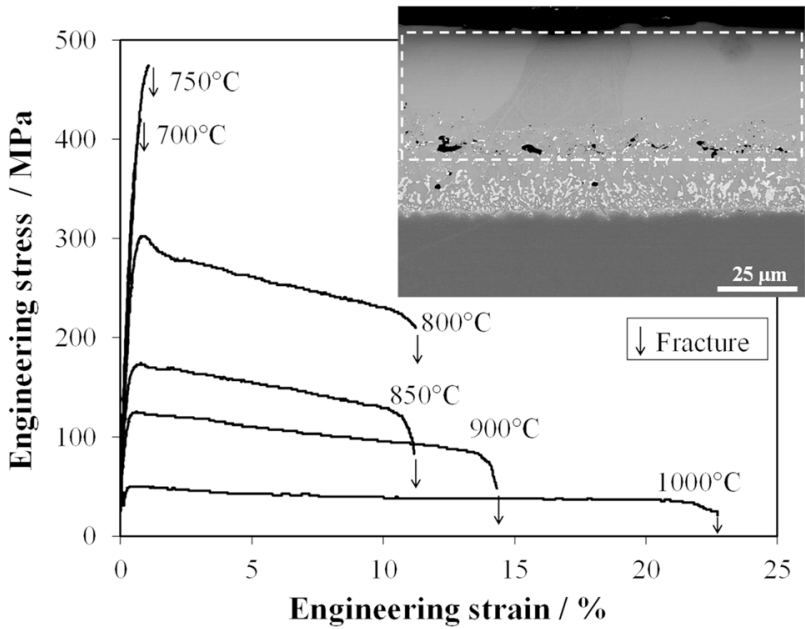

(b)

Fig. 1-(a) Gradient of chemical composition within the different layers of the $\beta$-Pt-modified NiAl coated AM1 superalloy, i.e., the bond-coating (B.C.), the interdiffusion zone (ID.Z.), and the AM1 monocrystalline superalloy (S.X.), (b) Stress-strain curves of the $\beta$-Pt-modified NiAl bondcoating (B.C.) between $700^{\circ} \mathrm{C}$ and $1000^{\circ} \mathrm{C}$. The insert on the top right corresponds to the cross-section observation of the $\beta$-(Ni,Pt)Al bondcoated AM1 SX superalloy. The white dashed box corresponds to the position of the freestanding bond-coating specimens in terms of depth and thickness. 
superalloy, resulting from the grit blasting of the nickelbased superalloy for adherence purposes. Chemical composition profiles of the different elements constitutive of the bond-coating and the AM1 substrate were obtained with EDS analyses and are depicted in Figure 1(a). The external bond-coating was found relatively homogeneous in composition for $\mathrm{Ni}, \mathrm{Al}$ and Pt.

Ribbon-shape microtensile specimens $(35 \mathrm{~mm}$ long and $2 \mathrm{~mm}$ wide specimens) were first extracted from the coated single-crystal superalloy with the longitudinal direction parallel to the withdrawal direction of the AM1 single-crystal superalloys, i.e. the $\langle 001\rangle$ crystallographic direction. Freestanding specimens from the bond-coating, the interdiffusion zone and the substrate were then prepared by a gentle mechanical abrasion technique using a PP5GT precision Jig and a CL50 lapping machine from LOGITECH limited. A detailed procedure for the specimen preparation is fully described in References 22 and 28. The freestanding specimens were $35 \pm 1 \mu \mathrm{m}$ thick with a variation in thickness about $\pm 0.5 \mu \mathrm{m}$ along the specimen gage. A particular attention was paid during the specimen preparation from each layer, i.e., the bond-coating, the interdiffusion zone and the substrate, in order to insure similar specimen extraction in terms of thickness and position in the depth of this graded microstructure system with less than $1 \mu \mathrm{m}$ geometrical tolerances.

High temperature micromechanical tests were conducted on the freestanding specimens at elevated temperature under specific controlled atmosphere (1.2 bar high purity Ar static atmosphere combined with oxygen getter made of particles of $\mathrm{Zr}$ ). Owing to the high surface/volume ratio, a particular attention was paid on the controlled atmosphere to avoid surface damages (high temperature oxidation, sublimation, nitriding, elemental depletion) thus affecting the mechanical characterization of the microtensile specimens. The readers are referred to References 22, 28, 29 and 30 for more details. Tensile tests were performed in a temperature range of $700{ }^{\circ} \mathrm{C}$ to $1000{ }^{\circ} \mathrm{C}$ with a strain rate of $1 \times 10^{-4} \mathrm{~s}^{-1}$. The macroscopic stress-strain response of the $\beta$ - $(\mathrm{Ni}, \mathrm{Pt}) \mathrm{Al}$ bond-coating in this range of temperatures was investigated and depicted in Figure 1(b).

At $700^{\circ} \mathrm{C}$, the $\beta$-(Ni,Pt)Al bond-coating exhibits a fragile behavior on the whole deformation domain with a fracture stress at $420 \mathrm{MPa}$ while an onset of plasticity was noticed at $450 \mathrm{MPa}$ at $750^{\circ} \mathrm{C}$ with a fracture stress at $475 \mathrm{MPa}$. At $800^{\circ} \mathrm{C}$, the ductility of the $\beta$-(Ni,Pt)Al bond-coating significantly increased (strain-to-failure $($ S.T.F.) $=12$ pct) and the mechanical strength dropped-off. The ultimate tensile strength is about $300 \mathrm{MPa}$ at $800^{\circ} \mathrm{C}$ for a macroscopic strain of 0.8 pct. A slight softening is noticed when increasing the plastic strain, leading to a fracture stress at $220 \mathrm{MPa}$. At higher temperatures, the ultimate tensile strength continued to decrease down to $50 \mathrm{MPa}$ at $1000{ }^{\circ} \mathrm{C}$. Strain-to-failure of the $\beta-(\mathrm{Ni}, \mathrm{Pt}) \mathrm{Al}$ bond-coating was found to be $23 \mathrm{pct}$ at this latter temperature. The present $\beta$ - $(\mathrm{Ni}, \mathrm{Pt}) \mathrm{Al}$ bondcoating demonstrated a clear brittle-to-ductile transition (BDTT) behavior at $\approx 750{ }^{\circ} \mathrm{C}$. This brittle-to-ductile transition behavior for the present bond-coating is in good agreement with the literature for nickel aluminide ${ }^{[6,9,10,14,17,18]}$ and Pt-modified nickel aluminide ${ }^{[7,8,19,20,23,25]}$ coatings. The main difference for the different nickel aluminide bond-coatings is the temperature at which the BDTT occurs, depending on the chemistry of the bond-coating. For instance, high temperature low activity (LTHA) aluminide coatings demonstrate higher BDTT values in comparison with low temperature high activity (HTLA) aluminide coatings. ${ }^{[6]}$ Furthermore, addition of platinum in nickel aluminide coatings was found to significantly increase the BDTT. ${ }^{[6,8]}$ The macroscopic tensile properties obtained in the present investigation, i.e. the Young's Modulus, the 0.2 pct offset yield strength (Y.S.), the ultimate tensile strength (U.T.S.), and the strain-tofailure (S.T.F.), were compared to the literature in Figure 2. Differences in the mechanical behavior (stress-strain response) of the bond-coatings were found especially in the plastic domain, depending on the characterization techniques but also the potential difference in chemical composition of the bond-coatings.

The Young's Modulus of the $\beta-(\mathrm{Ni}, \mathrm{Pt}) \mathrm{Al}$ bondcoating was found to decrease with the temperature increase in the whole temperature range. The elastic response of the present bond-coating was found intermediate compared to the one tested by Pan et al. ${ }^{[7]}$ (blue and empty diamonds) and Alam et al. ${ }^{[8]}$ (green circles for the 5 PtAl specimen), as depicted in Figure 2(a). For information, blue diamonds correspond to Young's modulus values fitted from the high temperature tensile curves whereas the empty diamond correspond to the equation given in the same Reference 7 as an extrapolation of the low temperature Young's moduli $\left(T \in[25-500]^{\circ} \mathrm{C}\right)$. In the present investigation, the elongation measurement considers the relative displacement of the grips using non-contact extensometry. The measured elastic modulus could thus be affected and lowered due to the compliance of the gripping system. As far as the onset of plasticity is concerned, the 0.2 pct. offset yield strength of the present bond-coating is in very good agreement with the one obtained by Alam et al. ${ }^{[8]}$ but higher than the one obtained by Pan et al. ${ }^{[7]}$ (Figure 2(b)). This difference in yielding behavior could arise from the $\mathrm{Pt}$ addition in the aluminide bond-coating and/or the difference in $\mathrm{Ni} / \mathrm{Al}$ ratio, playing a role on the BDTT value and potentially on the strengthening effect. Beyond the BDTT, the present bond-coating demonstrated a slight softening in the plastic domain, the softening being less and less pronounced when the temperature increases. This softening at high temperature could be related to thermally activated diffusion and creep processes. Creep processes can be also affected with the deviation from the stoichiometry of the intermetallic compound, as reported by Sauthoff et al. ${ }^{[31]}$ This softening after the ultimate tensile strength has also been evidenced by Alam et al. ${ }^{[8,20]}$ but differs due to the progressive stress decrease down to zero load at failure. Interestingly, the high ductility obtained in this study is one order of magnitude higher than previous results from literature ${ }^{[7,8,19,20]}$ (Figure 2(c)). 


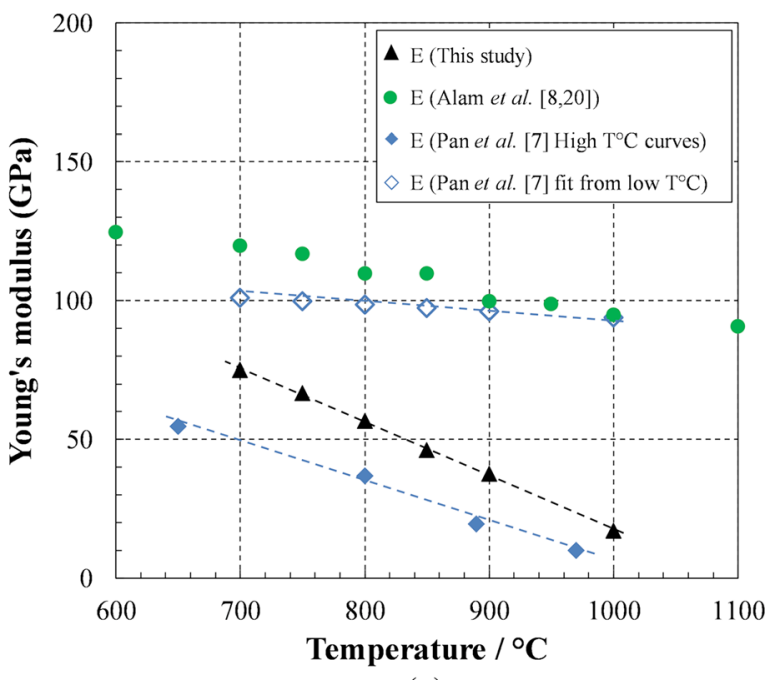

(a)

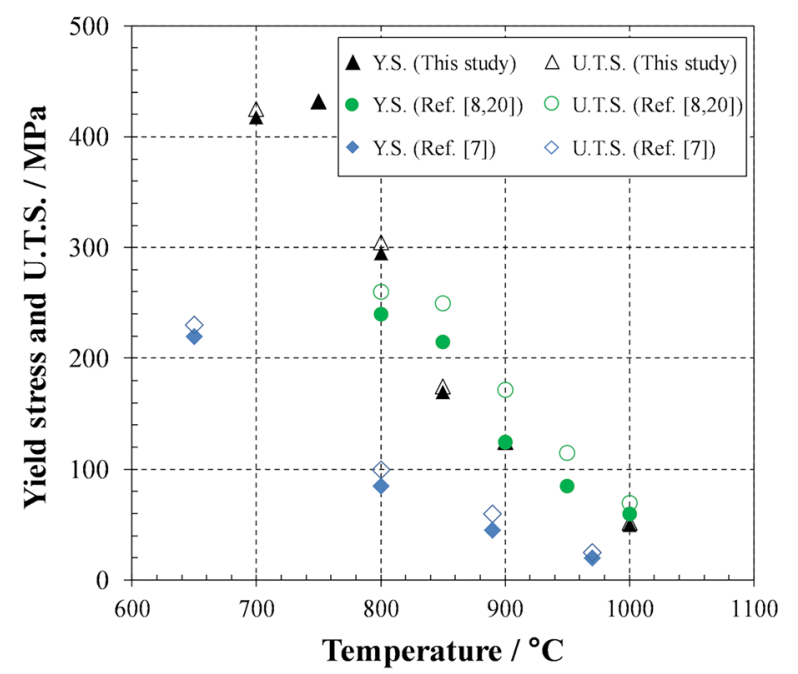

(b)

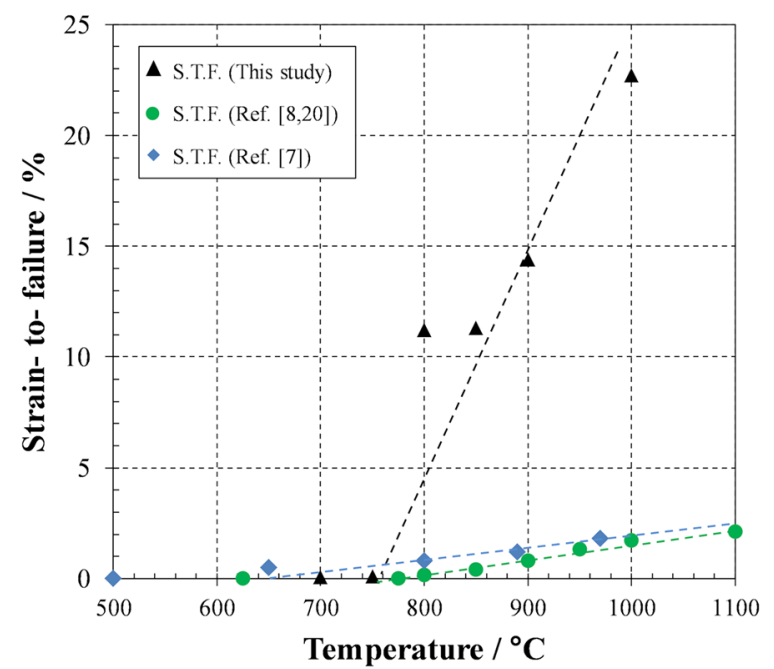

(c)

Fig. 2-Evolution of the macroscopic tensile properties of the $\beta$-Ptmodified NiAl bond-coating (B.C.) compared with the literature: (a) Young's modulus, (b) yield strength (filled markers) and ultimate tensile (empty markers) strength, and $(c)$ strain-to-failure.
This higher ductility is consistent with the fact that no cracks are noticed in the bond-coatings when coated superalloys are tested at temperature higher than the $\mathrm{BDTT}^{[6,9,10,14,17,25]}$ or on freestanding bond-coating using miniaturized disc bending testing. ${ }^{[18]}$ Therefore, the high ductility obtained in the present investigation better match the deformation response of the layers of the whole TBC systems.

Fractographic observations were conducted on specimen tested below and above the BDTT using a LEO435VP scanning electron microscope (SEM) in a secondary electrons mode (see e.g. Figure 3). For temperature below the BDTT, coarse cleaved grains without necking clearly justified the brittleness of the material up to $750^{\circ} \mathrm{C}$. The brittle fracture of the $\beta$ $(\mathrm{Ni}, \mathrm{Pt}) \mathrm{Al}$ bond-coating is due to cleavage microcrack nucleation at grain boundaries generated from the shear stress inferred by the pile-up of dislocations and nontransmission of slip deformation $(\{01 \overline{1}\}\langle 011\rangle$ and $\{100\}\langle 100\rangle$ slip systems) from an adjacent grain. Straight dislocations should only be observable in few grains, the majority of the grains being devoid of dislocations. This mechanism, well reported for B $\beta$ $\mathrm{NiAl}$ phase, ${ }^{[32]}$ was found not to be affected by $\mathrm{Pt}$ addition up to 15 pct atomic based on fractographic and transmission electron microscopy observations. ${ }^{[8]}$ It is worth noting that both the freestanding bondcoating specimens and the coated superalloy specimens depict similar fracture features below and above the BDTT. This result confirms the validity of microtensile freestanding specimens for assessing both the mechanical behavior of the bond-coating but also to sound the deformation and damage mechanisms. At temperatures above $750{ }^{\circ} \mathrm{C}$, an important necking of individual grains, tearing features and voids were noticed on the fracture surface of the specimens. Such fracture features are consistent with the highly ductile behavior of the bond-coating. Similar damage mechanisms were observed by Alam et al. ${ }^{[8]}$ This latter study also reported an intensification of dislocations and recrystallization after deformation at high temperatures.

The accurate positioning at specific depths of the specimen extraction process allows the mechanical characterization of the different layers of the coated superalloys, i.e. the bond-coating (B.C.), the interdiffusion zone (ID.Z.) and the substrate (S.X.). ID.Z. and S.X. demonstrate similar stress-strain responses, as recently reported for another coated system. ${ }^{[29]}$ Due to the intense strain localization in monocrystalline materials, which affects the AM1 but also its interdiffusion layer, the present specimen geometry and macroscopic extensometry is not well suited to document the plastic behavior of the S.X. and ID.Z., as already reported in Reference 29. However, the yielding behavior could be assessed with a good degree of confidence and and the present investigation allows the comparison between the different layers. The mechanical performance of both the S.X. and the ID.Z. decreases with the temperature increase (Figure 4). The ID.Z. exhibits an intermediate 


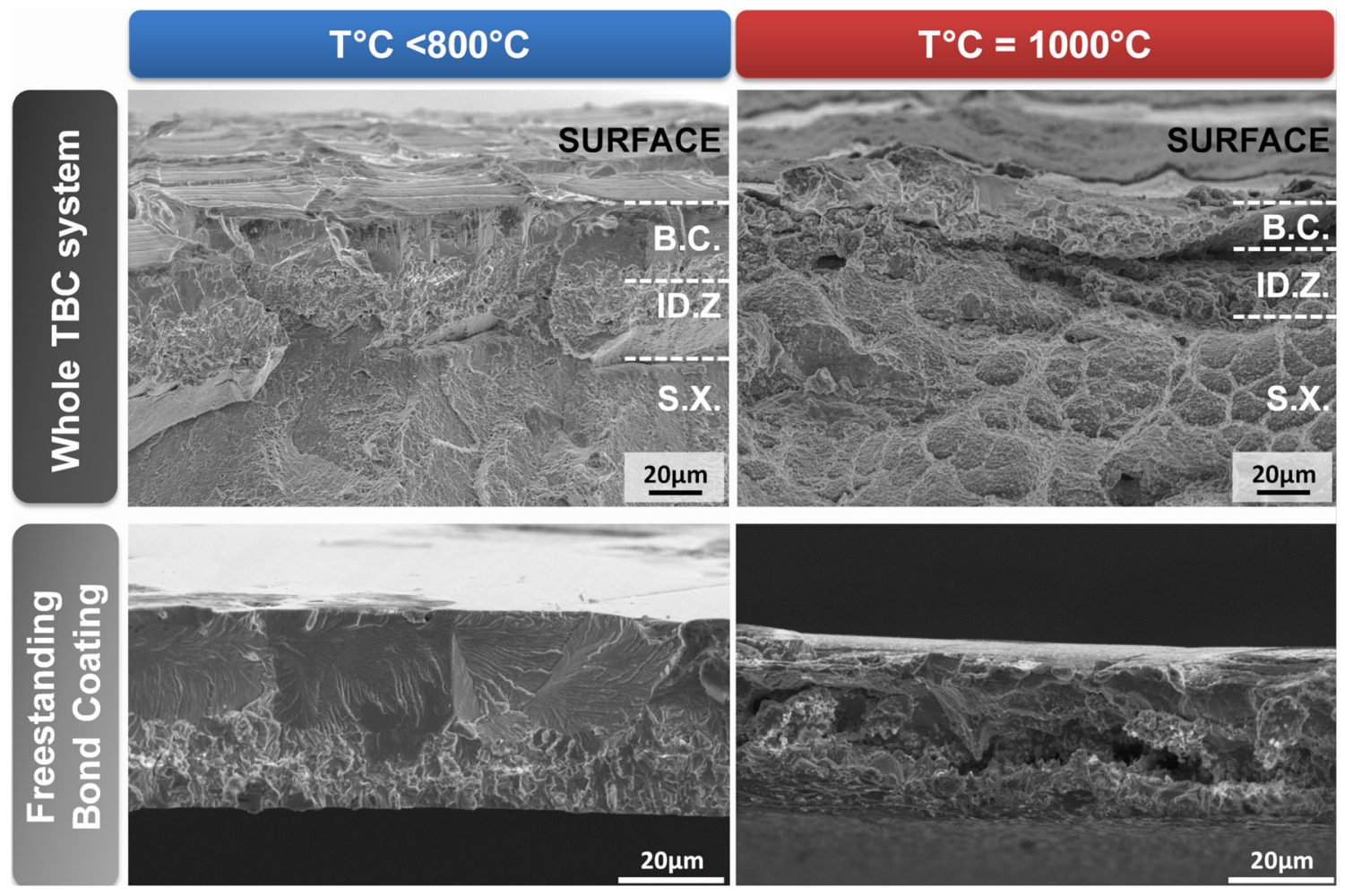

Fig. 3-Fracture surfaces of the $\beta$-Pt-modified NiAl bond-coating (B.C.) tested at different temperatures below and above the BDTT. Fracture surfaces of freestanding bond-coating specimens were compared with the ones of whole TBC systems and show high similarities.

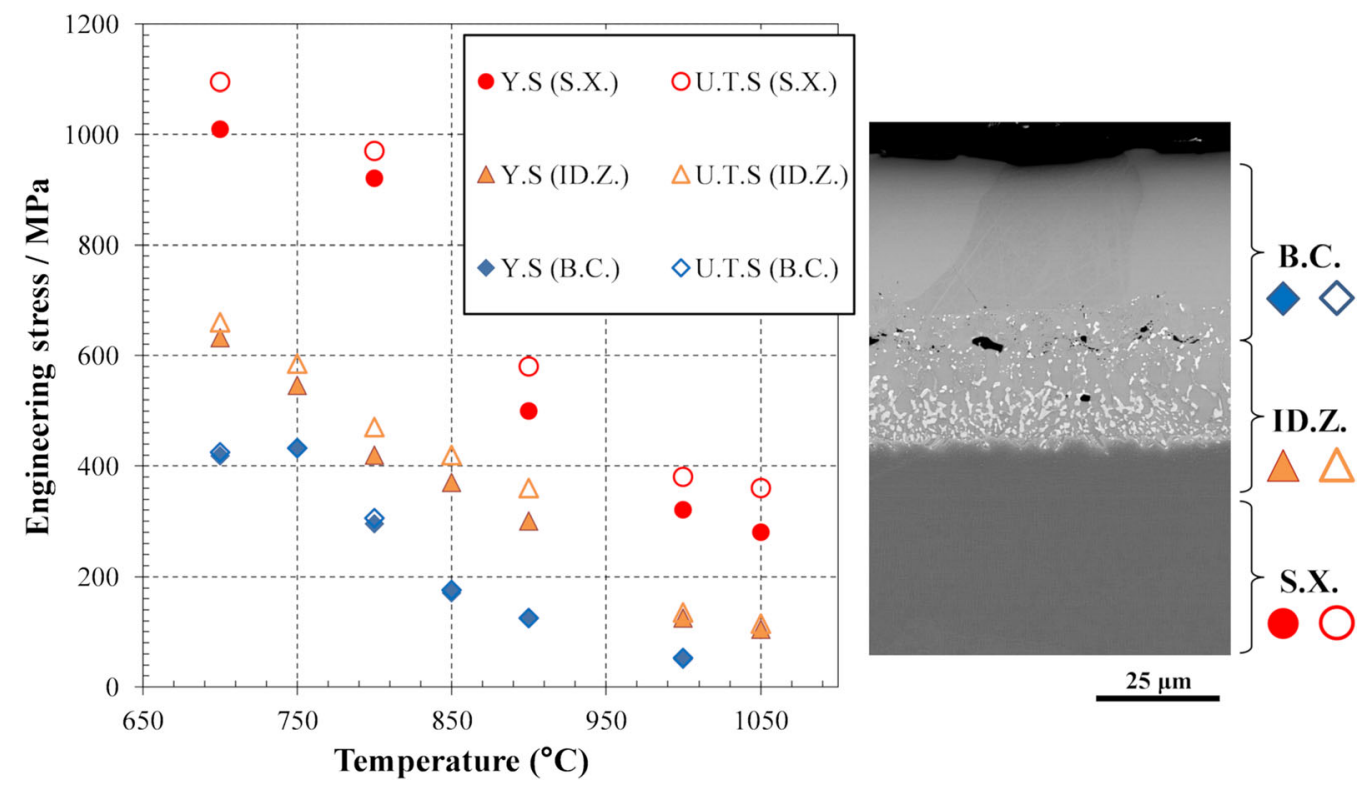

Fig. 4-Evolution of the macroscopic tensile strength properties within the gradient of microstructure, i.e., the $\beta$-Pt-modified NiAl bond-coating (B.C.), the interdiffusion zone (ID.Z.) and the AM1 superalloy substrate (S.X.).

tensile behavior between B.C. and S.X., thus playing the role of accommodation zone in such a layered structure with a strong difference in thermomechanical behavior.
Both S.X. and ID.Z. are more sensitive to strain localization due to the single-crystal nature of the substrate and lead to lower ductility in comparison with 
bulky S.X. specimens and freestanding B.C. specimens. In addition, the dendrite structure of the monocrystalline superalloy could also affect the high temperature mechanical properties when specimens are thinner than the dendritic pattern. ${ }^{[30]}$ Such database is not available to date due to complexity of high temperature micromechanical testing. For instance, Pollock et al. ${ }^{[13]}$ used a parametric numerical simulation of the layered microstructure (B.C. + ID.Z. + S.X.) in order to evaluate the influence of various properties of the ID.Z. and the B.C. on the different stages of oxide-assisted crack propagation rate within the B.C., the ID.Z., then the S.X. The result of these simulations clearly suggests that "the properties of the oxide, coating, and ID.Z. may have an unexpectedly strong effect on airfoil life", thus justifying the necessity of such data assessment.

As a summary, the gradient of high temperature mechanical properties was characterized for the first time in the reference $\beta$ - $(\mathrm{Ni}, \mathrm{Pt}) \mathrm{Al}$ coated $\mathrm{AM} 1$ nickelbased single-crystal superalloy system. While the interdiffusion zone and the substrate specimens exhibit a ductile behavior from $700^{\circ} \mathrm{C}$ to $1050{ }^{\circ} \mathrm{C}$, the bondcoating demonstrated a brittle-to-ductile transition at $\approx 750^{\circ} \mathrm{C}$. The interdiffusion zone has a tensile strength $200 \mathrm{MPa}$ higher than the bond-coating on the investigated temperature domain. However, the tensile strength of the interdiffusion zone and the bond-coating are sufficiently low compared to the superalloy to consider them as non-load-bearing but weighing regions for structural calculations of the superalloy substrate. Nevertheless, assessing local mechanical properties within the gradient of microstructure of the system may be useful for the understanding of the integrity of coated airfoil blades. For example, the modeling of oxide-assisted crack extension under thermal and/or mechanical fatigue stresses and the prediction of rumpling and buckling phenomena requires such data.

The authors are particularly grateful to Safran Aircraft Engines for providing the materials and financial support. This work was part of a research program supported by DGA involving Safran Aircraft Engines, Safran Helicopter Engines, ONERA, CEAT, and CNRS laboratories (Mines Paris Tech, Institut Pprime-ENSMA, LMT-Cachan, LMS-X, CIRIMATENSIACET).

\section{CONFLICT OF INTEREST}

The authors declare that they have no conflicts of interest.

\section{REFERENCES}

1. S. Bose: High Temperature Coatings, 1st ed., Butterworth-Heinemann, Oxford, 2007.

2. P.K. Wright and A.G. Evans: Curr. Opin. Solid State Mater. Sci., 1999, vol. 4, pp. 255-65.

3. T. Strangman, D. Raybould, A. Jameel, and W. Baker: Surf. Coat. Technol., 2007, vol. 202 (4), pp. 658-64.

4. C.G. Levi, J.W. Hutchinson, M.-H. Vidal-Sétif, and C.A. Johnson: MRS Bull., 2012, vol. 37 (10), pp. 932-41.

5. H. Evans: Surf. Coat. Technol., 2011, vol. 206 (7), pp. 1512-1521.

6. J.R. Nicholls: JOM, 2000, vol. 52 (1), pp. 28-35.

7. D. Pan, MW. Chen, P.K. Wright, and K.J. Hemker: Acta Mater., 2003, vol. 51 (8), pp. 2205-17.

8. M.Z. Alam, S.V. Kamat, V. Jayaram, and D.K. Das: Acta Mater., 2014, vol. 67, pp. 278-96.

9. K. Schneider and H. Grunling: Thin Solid Films, 1983, vol. 107, pp. 395-416.

10. J. Veys and R. Mevrel: Mater. Sci. Eng., 1987, vol. 88, pp. 253-60.

11. M. Wood: Mater. Sci. Eng. A, 1989, vol. 121, pp. 633-43.

12. A.G. Evans, M.Y. He, A. Suzuki, M. Gigliotti, B. Hazel, and T.M. Pollock: Acta Mater., 2009, vol. 57 (10), pp. 2969-83.

13. T.M. Pollock, B. Laux, C.L. Brundidge, A. Suzuki, and M.Y. He: J. Am. Ceram. Soc., 2011, vol. 94 (S1), pp. s136-45.

14. A. Strang, E. Lang, Effect of coatings on the mechanical properties of superalloys: in High Temperature Alloys for Gas Turbines 1982, pp. 469-506.

15. D. Balint and J. Hutchinson: J. Mech. Phys. Solids, 2005, vol. 53, pp. $949-73$

16. J.-R. Vaunois, J.-M. Dorvaux, P. Kanouté, and J.-L. Chaboche: Eur. J. Mech. A, 2013, vol. 42, pp. 402-21.

17. J. Veys, Contribution a l'étude de l'influence des revêtements protecteurs sur les propriétés mécaniques des superalliages pour aubes CMSX-2 et COTAC 784: Ph.D. thesis. Université de Poitiers (France) (1987).

18. M. Eskner and R. Sandstrom: Surf. Coat. Technol., 2003, vol. 165, pp. 71-80.

19. Z. Alam, D. Chatterjee, S. Kamat, V. Jayaram, and D. Das: Mater. Sci. Eng. A, 2010, vol. 527 (26), pp. 7147-50.

20. M.Z. Alam, S. Kamat, V. Jayaram, and D.K. Das: Acta Mater., 2013, vol. 61 (4), pp. 1093-1105.

21. D. Texier, Mesure et évolution des gradients de propriétés mécaniques dans le système superalliages à base de nickel MC2 revêtu MCrAlY: Ph.D. thesis. Université de Toulouse (France) (2013).

22. D. Texier, D. Monceau, J.-C. Salabura, R. Mainguy, and E. Andrieu: Mater. High Temp., 2016, vol. 33 (4-5), pp. 325-37.

23. B. Passilly, P. Kanoute, F.-H. Leroy, and R. Mévrel: Philos. Mag., 2006, vol. 86 (33-35), pp. 5739-52.

24. A. Villemiane, Analyse du comportement mécanique d'alliages pour couches de liaison de barrière thermique par microindentation instrumentée à haute température: Ph.D. thesis. INP Lorraine (2008).

25. M.P. Taylor, H.E. Evans, E.P. Busso, and Z.Q. Qian: Acta Mater., 2006, vol. 54 (12), pp. 3241-52.

26. R. Hüttner, J. Gabel, U. Glatzel, and R. Völkl: Mater. Sci. Eng. A, 2009, vols. 510-511, pp. 307-11.

27. J. Benoist, K. Badawi, A. Malié, and C. Ramade: Surf. Coat. Technol., 2004, vol. 182 (1), pp. 14-23.

28. D. Texier, D. Monceau, Z. Hervier, and E. Andrieu: Surf. Coat. Technol., 2016, vol. 307, pp. 81-90.

29. D. Texier, D. Monceau, F. Crabos, and E. Andrieu: Surf. Coat. Technol., 2017, vol. 326, pp. 28-36.

30. D. Texier, D. Monceau, R. Mainguy, and E. Andrieu: Adv. Eng. Mater., 2014, vol. 16 (1), pp. 60-64.

31. G. Sauthoff: Intermetallics, Wiley, New York, 1995, p. 165.

32. D. Miracle: Acta Metall. Mater., 1993, vol. 41 (3), pp. 649-84. 